\title{
QUANTIFICATION OF PHYTOCHEMICAL CONSTITUENTS AND IN VITRO ANTIOXIDANT ACTIVITY IN THE LEAVES OFCITRUS MEDICA
}

\author{
MAYAVATIS PATIL \\ Department of Biotechnology, Government Institute of Sciences, Aurangabad 431004 \\ Email: patilmsgis@gmail.com
}

Received: 23 May 2017, Revised and Accepted: 22 Jul 2017

\begin{abstract}
Objective: In the present investigation, phytochemical assay and in vitro antioxidant activity of ethanol (70\%), methanol, ethyl acetate and hexane extract of Citrus medica leaves were carried out.

Methods: The quantification of total phenolic and alkaloid contents were estimated by taking gallic acid and atropine as standard. In-vitro antioxidant activity of extracts was evaluated by using different free radicals (DPPH, superoxide and free radicals).

Results: Ethanol extract of leaves have more phenolic and alkaloid contents than other extracts. The selected plant extract was produced concentration dependent percentage inhibition of different free radicals and produced maximum activity at a concentration of $1000 \mu \mathrm{gm} / \mathrm{ml}$, and there after percentage inhibition was raised gradually to its maximum level with higher concentrations. HPLC analysis revealed the presence of Gallic acid, Catechein, Rutin, Chlorgenic acid, Queracetine and some unknown components which need to be e identified.
\end{abstract}

Conclusion: Among the four extracts, ethanol extract of $C$. medica showed good antioxidant activity.

Keywords: Alkaloids, Antioxidant, Citrus medica, HPLC, Phenolics

(C) 2017 The Authors. Published by Innovare Academic Sciences Pvt Ltd. This is an open access article under the CC BY license (http://creativecommons.org/licenses/by/4.0/) DOI: http://dx.doi.org/10.22159/ijcpr.2017v9i5.22153

\section{INTRODUCTION}

Since long back human civilization is using plant and plant derived products as a source of medicine. As the plants possess potent activity against several diseases, in the recent scientific developments so many medicinal properties of such plants have been investigated throughout the world. It possesses another advantage like no side effects and economic feasibility. Many plants species are reported to synthesize certain secondary metabolites with important medicinal properties which include antioxidant activity, free radical scavenging abilities, anti-carcinogenic antiinflammatory, etc. [1]. Hence recently, natural plants are getting ample attention of researchers for sources of biologically active substances like antioxidants. A vast studies is already being carried out on several plants, vegetables and fruits which are rich sources of antioxidants, like vitamin A, vitamin C, Vitamin E, carotenoids, polyphenolic compounds and flavonoids which reported to prevent free radical damage, reducing the risk of chronic diseases [2]. During normal metabolic activities in a human cell, various physiological and biochemical reactions generate free radicals and other reactive oxygen species (ROS) as the by-products. Free radicals are chemical species, which contains one or more unpaired electrons due to which they are highly unstable and cause damage to other molecules by extracting electrons from them in order to attain stability and thus can cause oxidative damage to important biomolecules like proteins lipids in living cell, ultimately leading to many chronic diseases, such as cancer, diabetes, aging, and other degenerative diseases in humans [3]. Thus ROS have been found to play an important role in several diseases such as ageing, atherosclerosis, inflammatory injury, cancer, and cardiovascular disease [4].

Phytochemical assay of crude extracts of several plants reported to bear the antioxidant activity $[5,6]$. As a result, some natural products of such plants have been approved as antioxidant drugs. Antioxidant activity of plants mainly results of presence secondary metabolites, such as flavonoids, phenolic acids, tannins, and phenolic diterpenes [7, 8]. In the present study quantification of phytochemical constituents and antioxidant potential of leaves a medicinal plant Citrus medica (Lemon), is aimed. Based on the review about the therapeutic values of Citrus medica, the present study was attempted to screen the phytochemicals, their quantification and analysis $[9,10]$.
The Citrus medica (Citron) isa plant with fragrant fruit and leaves. It is a prominent member in the genus Citrus belonging to the Rutaceae or Rue family, found in the base region of Himalaya from Gadwall to Sikkim at the height of 4000 feet. It is also seen in Assam, central India and Western Ghats of India and more commonly present in the Mediterranean region and central and southern parts of America [9]. This study represents the first approach for characterization of phytochemicals of Citrus medica leaves. The fruit juice of Citrusmedica exerts antimutagenicity and anticancer effect [11]. Its aqueous and alcoholic extracts were found to be active as anthelmintic with reference to both the paralysis and death times as compared to the piperazine citrate. The aqueous extract is more active than alcoholic extract. Phytochemical screening states that it contains fixed oils, volatile oils, citric oxide and flavanone glycosides are abundant constituents of citrus leaves and fruits [12].

\section{MATERIALS AND METHODS}

\section{Chemicals and drugs}

All chemicals and solvents were of analytical grade obtained from Hi-media Mumbai, SD Fine Chemicals Pvt. Ltd., Mumbai, Sigma Chemical Company, U. S. A., Loba chemicals, Mumbai.

\section{Preparation of extracts from Citrus medica leaves}

The fresh plant material used in the present study was collected from one agro field in Aurangabad district, M. S., India. It is authenticated by the taxonomist of Botany Department of Institute of Science, Aurangabad, M. S., India. Freshly collected plant material was dried under shade and dried material was crushed to obtain a coarse powder. The powdered material was separately extracted in a soxhlet apparatus for $6 \mathrm{~h}$ successively with hexane, ethyl acetate, $70 \% \mathrm{v} / \mathrm{v}$ ethanol and methanol was concentrated to dryness under vacuum by using Rota-vapor.

\section{Phytochemical studies}

Phytochemical studies were carried out for hexane, ethyl acetate, hydro alcoholic ( $70 \% \mathrm{v} / \mathrm{v}$ ethanol) and methanol extracts of $C$. medica to detect the presence of different phytochemical constituents like alkaloids, steroids, terpenoids, tannins, flavonoids, saponins, glycosides, amino acids etc. by using standard procedure [13-15] 


\section{Quantification of total phenolic content}

Total phenolic content was determined using the Folin-Ciocalteau reagent [16]. Singleton et al. Folin-Ciocalteau colorimetry is based on a chemical reduction of the reagent having a blue absorption with a maximum at $765 \mathrm{~nm}$. The intensity of light absorption at that wave length is proportional to the concentration of phenols. By using standard gallic acid calibration curve, measure the concentration of phenolic content in gallic acid total equivalents using unit's mg/g (GAE).

\section{Quantification of total alkaloid content}

Total alkaloid content was determined by Fazel et al. [17] method. The plant extract $(1 \mathrm{mg} / \mathrm{ml})$ was dissolved in $2 \mathrm{~N} \mathrm{HCl}$ and then filtered. One $\mathrm{ml}$ of this solution was transferred to a separating funnel and then $5 \mathrm{ml}$ of BCG (bromocresol green) solution along with $5 \mathrm{ml}$ of phosphate bufferof $\mathrm{pH} 7$ were added. The mixture was shaken and the complex formed was extracted with chloroform by vigorous shaking. The extracts were collected in a $10 \mathrm{ml}$ volumetric flask and diluted to volume with chloroform. The absorbance of complex in chloroform was measured at $470 \mathrm{~nm}$. All experiments were performed thrice; the results were averaged and reported in the form of mean \pm SEM

\section{In vitro antioxidant activity}

For the assessment of free radical scavenging activity, the hexane, ethyl acetate, Ethanol $(70 \% \mathrm{v} / \mathrm{v})$ and methanol extracts were dissolved and $5 \%$ dimethyl sulphoxide (DMSO) respectively.

\section{Superoxide radical scavenging activity}

Superoxide scavenging activity of the plant extract was determined by McCord and Fridivich method [18], which depends on light induced superoxide generation by riboflavin and the corresponding reduction of nitroblue tetrazolium.

\section{Hydroxyl radical scavenging activity}

Hydroxyl radical scavenging activity is frequently used to evaluate the free radical scavenging effectiveness of various antioxidant substances [2]. It was measured by studying the competition between deoxyribose and the extracts for hydroxyl radicals generated from the $\mathrm{Fe}^{2+} / \mathrm{EDTA} / \mathrm{H}_{2} \mathrm{O}_{2}$ system. The hydroxide radical's attacks deoxyribose, which eventually results in the formation of thiobarbituric acid reacting substances.

\section{DPPH radical scavenging activity}

The scavenging activity for DPPH free radicals was measured according to the procedure described by [19]. This method is based on the reduction of alcoholic DPPH solution (dark blue in color) in the presence of a hydrogen donating antioxidant converted to the nonradical form of yellow colored diphenyl-picrylhydrazine. Lower the absorbance higher the free radical scavenging activity [20].

\section{HPLC analysis}

Separation and quantification of the various components in the ethanolic $(70 \% \mathrm{v} / \mathrm{v})$ extract was carried out using a reversed-phase high performance liquid Chromatographic system with the UV detector. (Younglin (S. K) isocratic System UV Detector i.e. having constant wavelength for detection) consisting of UV Detector andAutochro-3000 software. The size of column $4.6 \times 250 \mathrm{~mm}$ consisting of silica particles of diameter $5 \mu \mathrm{m}$ and modified with alkyl chain having 18 Carbons $\left(\mathrm{C}_{18}\right)$ (Grace) as the stationary phase. In pair formation agent ( $0.1 \%$ trifluoroacetic acid) enhances the retention of highly charged molecules due to charge compensation. The column was thermo stated at ambient temperature. Samplessize of $20 \mu \mathrm{l}$ were injected with flow rate $0.5 \mathrm{ml} / \mathrm{min}$. The initial mobile phase was a dilute aqueous solution consist of a mixture of water/acetic acid (98:2, $\mathrm{v} / \mathrm{v}$ ) was used (solvent A). Aqueous acetonitrile $(50: 50, \mathrm{v} / \mathrm{v})$ with 0.5 $\%$ (vol.) acetic acid additive was used as solvent B. Following gradient was used for elution: $10 \%$ of B at $0 \mathrm{~min}, 55 \%$ of $\mathrm{B}$ at $50 \mathrm{~min}, 100 \% \mathrm{f}$ $B$ at $60 \mathrm{~min}$ and $10 \%$ of B at $65 \mathrm{~min}$. A wavelength of $280 \mathrm{~nm}$ was used for the detection of gallic acid, chlorgenic acid, catechin, rutin, quercetin etc. as standard compounds. The identification of each compound was carried out comparing the retention time and UV-Vis spectra of the peaks with those previously obtained by the injection of standards. Each compound was quantified as $\mathrm{mg} / 100 \mathrm{~g}$ of dry sample material by using the peak area because peak area is proportional to the quantity of that compound in the sample [21].

\section{RESULTS AND DISCUSSION}

\section{Quantification of phytochemical constituents}

Quantified phenolic contents of Citrus medica leaves extracts were ranging from $42.45 \pm 0.48$ to $11.32 \pm 0.45 \mathrm{mg} / \mathrm{g}$. The ethanolic extracts $(70 \%)$ have found more phenolic content $(42.45 \pm 0.4845 \mathrm{mg} / \mathrm{g})$ than the other extracts. Alkaloid content was ranging from $47.65 \pm 0.46$ to $19.65 \pm 0.75 \mathrm{mg} / \mathrm{g}$. Here also ethanol extract $(70 \%)$ has more alkaloidal content $(47.65 \pm 0.46 \mathrm{mg} / \mathrm{g}$ ) than other extracts (table 1$)$.

Table 1: Total phenolic and alkaloid content $(\mathrm{mg} / \mathrm{g})$ of Citrus medica leaves extract

\begin{tabular}{lcl}
\hline Name of the extract & Total phenolic content $(\mathbf{m g} / \mathbf{g})$ & Total alkaloid content $(\mathbf{m g} / \mathbf{g})$ \\
\hline Hexane & $11.32 \pm 0.45$ & $19.65 \pm 0.75$ \\
Ethyl acetate & $23.5 \pm 0.24$ & $34.89 \pm 0.67$ \\
Methanol & $19.45 \pm 0.34$ & $27.67 \pm 0.54$ \\
Ethanol $(70 \% \mathrm{v} / \mathrm{v})$ & $42.45 \pm 0.48$ & $47.65 \pm 0.46$ \\
\hline
\end{tabular}

\section{In vitro antioxidant activity}

The results of the present research revealed that, the hexane, ethyl acetate, methanol and ethanol $(70 \% \mathrm{v} / \mathrm{v})$, extracts of Citrus medica leaves were found to possess concentration dependant scavenging activity on DPPH radicals (fig. 1). The mean IC 50 values for DPPH radical of hexane, ethyl acetate, methanol and ethanol $(70 \% \mathrm{v} / \mathrm{v})$, extracts of Citrus medica leaves were found to be $118 \mu \mathrm{g}, 134 \mu \mathrm{g}, 248$ $\mu \mathrm{g}, 345 \mu \mathrm{g}, 45 \mu \mathrm{g}$ respectively. The mean $\mathrm{IC}_{50}$ value for ascorbic acid was found to be $45 \mu \mathrm{g}$. (table 2).

The Ethanol (70\% v/v), methanolic, ethyl acetate and hexane extracts $C$. Indica leaves were found to possess concentration dependent scavenging activity on superoxide generated by photo reduction of riboflavin.(fig. 2). The mean $\mathrm{IC}_{50}$ values for superoxide radicals of hexane, ethyl acetate, methanol, ethanol $(70 \% \mathrm{v} / \mathrm{v})$ and ascorbic acid, extracts of Citrus medica leaves were found to be 245 $\mu \mathrm{g}, 123 \mu \mathrm{g}, 154 \mu \mathrm{g}, 296 \mu \mathrm{g}, 23 \mu \mathrm{g}$ respectively. The mean $\mathrm{IC}_{50}$ value for ascorbic acid was found to be $23 \mu \mathrm{g}$ (table 2).
The Ethanol $(70 \% \mathrm{v} / \mathrm{v})$, methanolic, ethyl acetate and hexane extracts M. Ferrea leaves were found to possess concentration dependent scavenging activity on hydroxyl radicals and the results were given (fig. 3). The mean $\mathrm{IC}_{50}$ values for hydroxyl radicals of hexane, ethyl acetate, methanol, ethanol $(70 \% \mathrm{v} / \mathrm{v})$ and ascorbic acid, extracts of Citrus medica leaves were found to be $189 \mu \mathrm{g}, 256$ $\mu \mathrm{g}, 287 \mu \mathrm{g}, 335 \mu \mathrm{g}$ and $64 \mu \mathrm{g}$ respectively (table 2). The mean $\mathrm{IC}_{50}$ value of ascorbic acid was found to be $59.3 \mu \mathrm{g}$ (table 2).

\section{HPLC analysis}

In order to identify the certain active component in the plant extracts sample, HPLC analysis was performed. As ethanolic extract was found to give more concentration dependent scavenging activity on DPPH radicals, superoxide radicals and hydroxyl radicals, it was subjected for HPLC analysis. The result of the above analysis showed the presence of compounds like Gallic acid, Catechein, Rutin, Chlorgenic acid, Queracetine and some unknown components which need to be identified. 


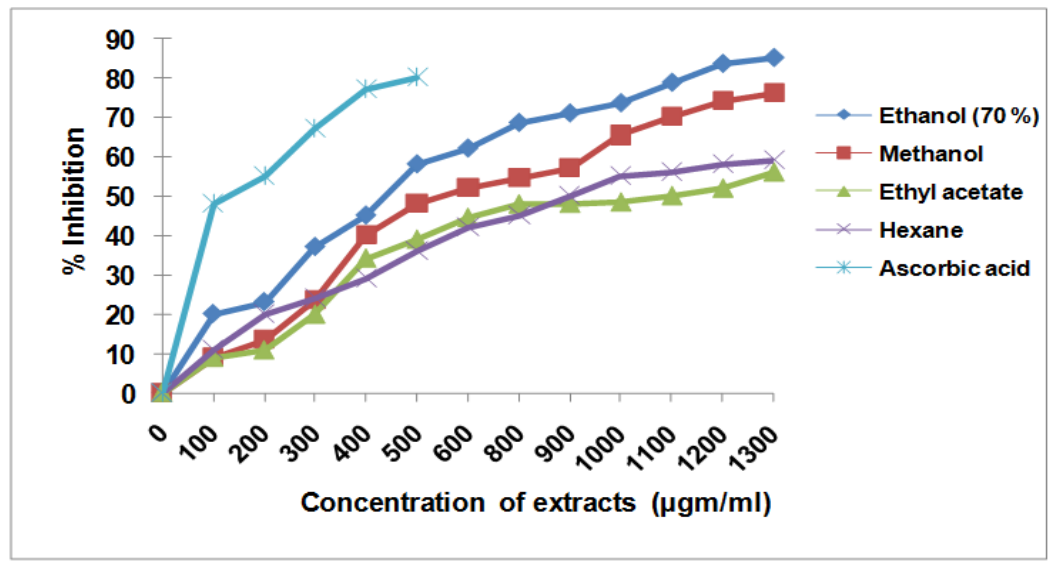

Fig. 1: Concentration dependent percent inhibition of DPPH radical by extracts of Citrus medica leaves and ascorbic acid

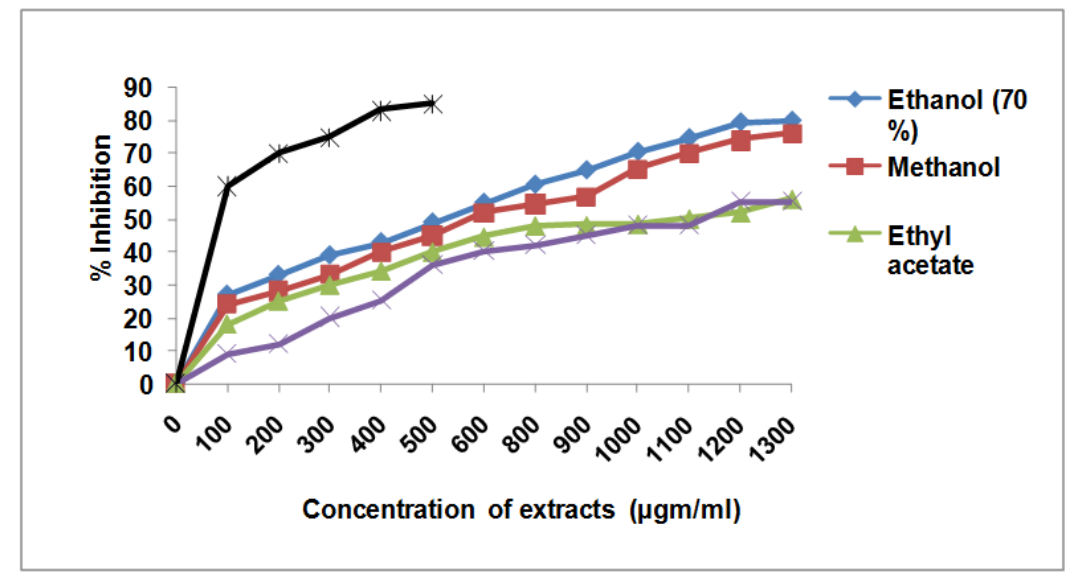

Fig. 2: Concentration dependent percent inhibition of superoxide radical by different extracts of Citrus medica leaves and ascorbic acid

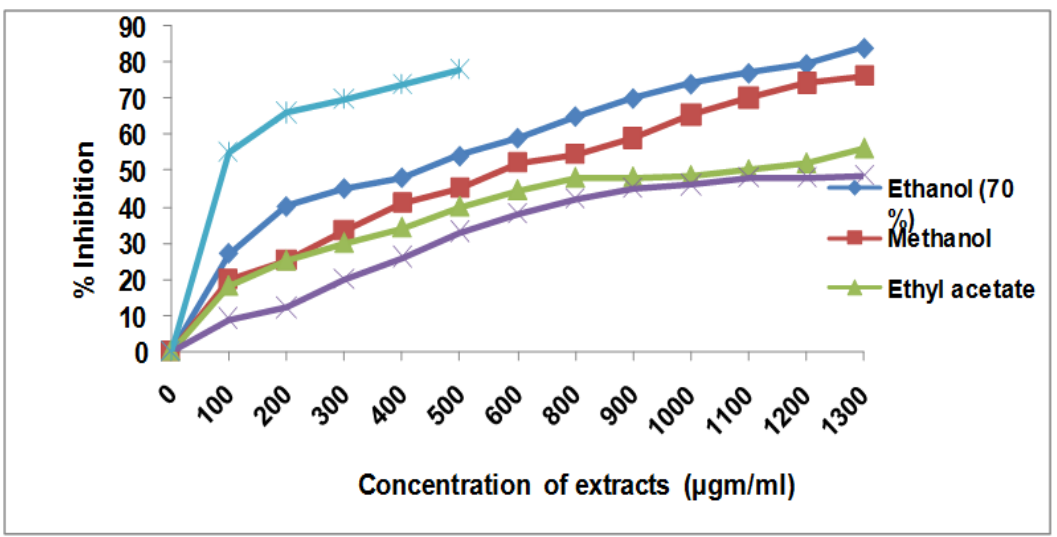

Fig. 3: Concentration dependent percent inhibition of hydroxyl radical by different extracts of Citrus medica leaves and ascorbic acid

Table 2: In vitro $50 \%$ inhibition concentration $\left(\mathrm{IC}_{50}\right)$ of different extracts of Citrus medica leaves on DPPH, superoxide and hydroxyl free radicals

\begin{tabular}{llll}
\hline Name of the extract & IC $_{\mathbf{5 0}}$ value $(\boldsymbol{\mu} \mathbf{g})$ & & Hydroxyl radical \\
\cline { 2 - 4 } & DPPH radical & Superoxide radical & 189 \\
\hline Hexane & 118 & 245 & 256 \\
Ethyl acetate & 134 & 123 & 287 \\
Methanol & 248 & 154 & 335 \\
Ethanol $(70 \% \mathrm{v} / \mathrm{v})$ & 345 & 296 & \\
\hline
\end{tabular}




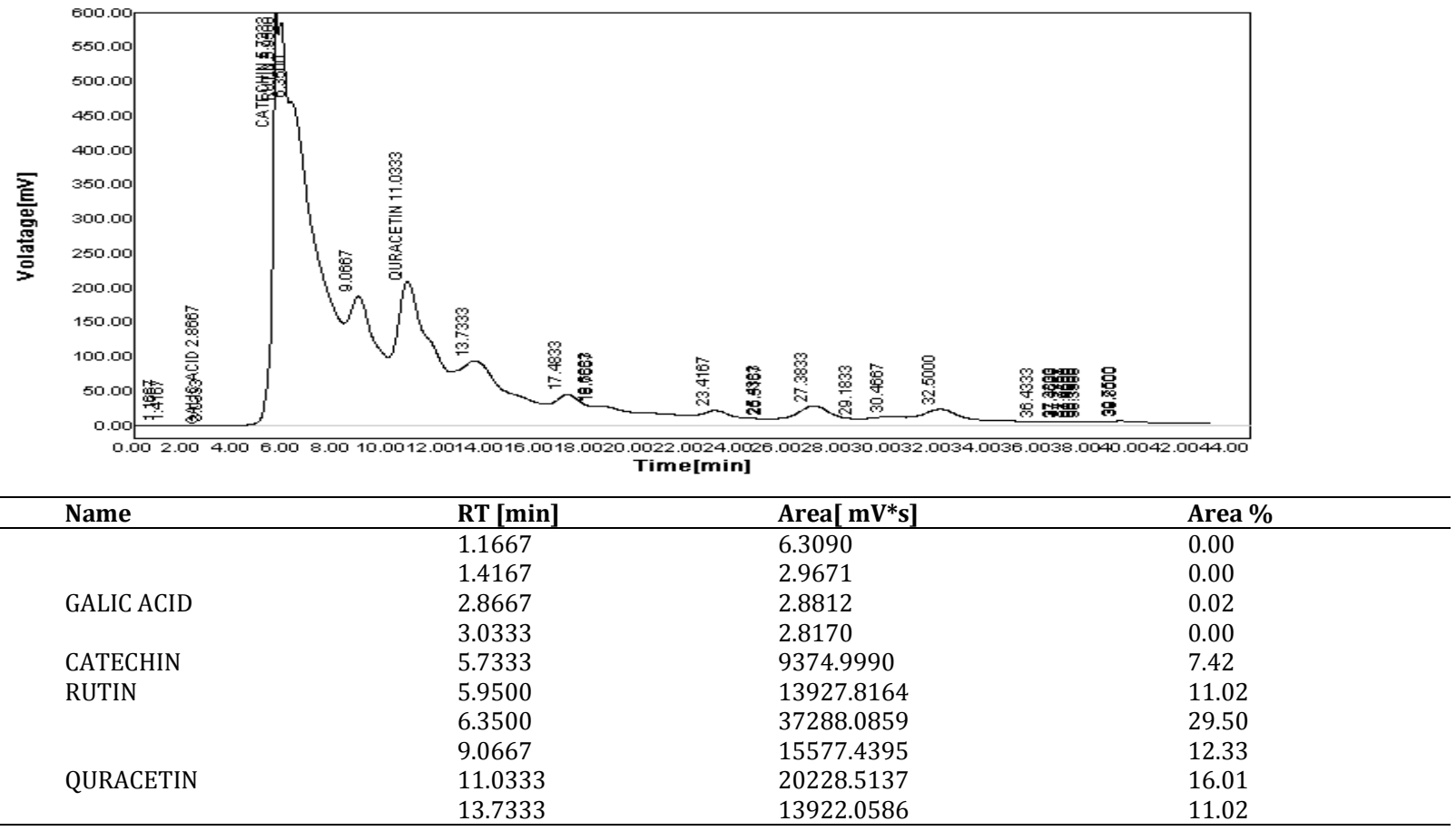

Fig. 4: HPLC profile report of ethanolic extract of Citrus medica

\section{CONCLUSION}

Various Chemical compounds viz. alkaloids, steroids, phenols, glycosides from Citrus medic plant are known to be useful in the treatment of many diseases [22]. Thus, leaves containing these compounds may serve as a potential source of bioactive compounds in the treatment of diseases.

The plant extracts prepared from leaves in various solvents showed presence very important compounds especially phenolic and alkaloids which have their medicinal uses in recent years. Alkaloids are related with medicinal uses for centuries including their role in cancer treatment [23]. The phenolic compounds in this plant may contribute to its antioxidant properties and thus the usefulness in herbal treatment [3]. Hence during the preparation of some antimicrobial and antioxidant compounds Phenols is found to use.

The results of phytochemical and HPLC suggests that the plant extract contain compounds that are capable of donating hydrogen to a free radical in order to remove odd electron which is responsible for Radical's reactivity. The plant extracts were capable of scavenging super oxide, hydroxyl and DPPH in a concentration dependent manner. The data clearly indicated that the extracts ethanol, methanol (70\%), hexane, ethyl acetate and of $C$. medica showed good antioxidant activity. Among the all the ethanol (70\%) extract showed better activity.

\section{CONFLICT OF INTERESTS}

\section{Declare none}

\section{REFERENCES}

1. Ganga RB, Rajeswararao P, Prayaga M, Sambasiva ER, Madhukiran $P$, Mallikarjuna TR. Investigation on regional variation in total phenolic, alkaloid content and in vitro antioxidant activity of Leucasaspera. Int J Curr Pharm Res 2011;2:2699-703

2. Prasad ND, Ganga Rao B, Sambasasiva Rao E, Mallikarjuna T. Quantification of phytochemical constituents and in vitro antioxidant activity of Meusaferrea leaves. Asian Pac J Trop Biomed 2012;12:S539-S542.

3. Olayinka A, Aiyegoro, Anthony IO. Preliminary phytochemical screening and in vitro antioxidant activities of the aqueous extract of Helichrysumlongifolium. BMC Complementary Altern Med 2010;10:21.

4. Halliwell B. Antioxidants and human diseases: a general introduction. Nutr Rev 1997;55:S44-S52.

5. Faraz M, Mohammad K, Narysanna G, Hamid. Phytochemical screening of some species of Iranian Plants. Iranian J Pharma Res 2003;3:77-82.

6. Edeoga HO, Okwu DE, Mbaere BO. Phytochemical constituents of some Nigerian Medicinal plants. Afr J Biotechnol 2005;4:685-6.

7. Daya L, Chothani, Patel NM. Preliminary phytochemical screening, pharmacognostic and physicochemical evaluation of leaf of Gmelinaarborea. Asian Pac J Trop Biomed 2012;12:S1333S1337.

8. Pietta PG. Flavonoids as antioxidants. J Nat Prod 2000;63:1035-42.

9. Meena AK, Kandale A, Rao MM, Panda P, Reddy GA. Review on citron-pharmacognosy, phytochemistry and medicinal uses. Int Res J Pharm 2011;2:14-9.

10. Onyeyirichi I, Ogechi N, Oche O, Jerry U, Gero M. Evaluation of chemical constituents of Citrus medicalimonum leaf essential oils. J Pharm Sci Innov 2014;3:306-9.

11. Satishkumar T, Baskar R. Screening and quantification of phytochemicals in the leaves and flower of Tabernaemontanaheyneana wall-a near the threatened medicinal plant, Indian J Nat Prod Res 2014;5:237-43.

12. Taha S, Alfy El, Mona H, Nemat Z, Yassin, Rehab F, et al. Estrogenic activity of Citrus medica L. leaves growing in Egypt. J Appl Pharma Sci 2012;8:180-5.

13. Faraz M, Mohammad K, Narysanna G, Hamid RV. Phytochemical screening of some species of Iranian Plants. Iranian J Pharma Res 2003;3:77-82.

14. Harborne B. Phytochemical methods: a guide to modern techniques of plant analysis. $3^{\text {rd }}$ editioin. Chapman and Hall, London, England; 1998.

15. Edeoga HO, Okwu DE, Mbaere BO. Phytochemical constituents of some Nigerian medicinal plants. Afr J Biotechnol 2005;4:685-6.

16. Singleton VL, Rossi JA. Colorimetry of total phenolics with phosphomolybdic acid-phosphotungstic acid reagents. Am J Ecol Viticulture 1965;16:144-58.

17. Fazel S, Hamidreza M, Rouhollah G, Mohammadreza VR. Spectrophotometric determination of total alkaloids in some Iranian medicinal plants. Thai J Pharm Sci 2008;32:17-20. 
18. McCord JM, Fridovich I. Superoxide dismutase: an enzymic function for erythrocuprein (hemocuprien). J Biol Chem 1969;244:6049-55.

19. Shang Tse Ho, Yu-Tang Tung, Kai-Chung Cheng, Jyh-Horng Wu. Screening, determination and quantification of major antioxidants from Balanophoralaxiflora flowers. Food Chem 2010;122:584-8.

20. Nurain A, Noriham A, Zainon MN Wan, Saidatul SWK, Khairusy SZ. Phytochemical constituents and bioactivities of aqueous extract of aromatic herbs. Int J PharmTech Res 2012;4:1401-6.

21. Wilson K, Walker J. Principle and techniques of biochemistry and molecular biology, Cambridge University Press. Sixth Edition. New York, USA; 2005. p. 486-513.
22. Cheenpracha S, Park EJ, Yoshida WY, Barit C, Wall M, Pezzuto JM. Potential anti-inflammatory phenolic glycosides from the medicinal plant Moringaoleifera fruits. Bioorg Med Chem 2010;18:6598-602.

23. Wet HD, Fouche G, Van Heerden FR. In vitro cytotoxicity of crude alkaloidal extracts of South African menispermaceae against three cancer cell lines. Afr J Biotechnol 2009;8:3332-5.

\section{How to cite this article}

- Mayavatis Patil. Quantification of phytochemical constituents and in vitro antioxidant activity in the leaves of Citrus medica. Int J Curr Pharm Res 2017;9(5):119-123. 